\title{
Application of a two-phase thermosyphon loop with minichannels and a minipump in computer cooling
}

HENRYK BIELIŃSKI*

JAROSEAW MIKIELEWICZ

The Szewalski Institute of Fluid-Flow Machinery Polish Academy of Sciences, Fiszera 14, 80-231 Gdańsk, Poland

\begin{abstract}
This paper focuses on the computer cooling capacity using the thermosyphon loop with minichannels and minipump. The one-dimensional separate model of two-phase flow and heat transfer in a closed thermosyphon loop with minichannels and minipump has been used in calculations. The latest correlations for minichannels available in literature have been applied. This model is based on mass, momentum, and energy balances in the evaporator, rising tube, condenser and the falling tube. A numerical analysis of the mass flux and heat transfer coefficient in the steady state has been presented.
\end{abstract}

Keywords: Thermosyphon loop; Two phase flow; Computer cooling

\section{Nomenclature}

$A \quad-\quad$ cross-section area of the channel, $\mathrm{m}^{2}$

$B$ - breadth, m

$D \quad$ - internal diameter of the tube, $\mathrm{m}$

$\dot{G} \quad-$ mass flux (mass velocity), $\mathrm{kg} /\left(\mathrm{m}^{2} \mathrm{~s}\right)$

$g \quad-$ gravitational acceleration, $\mathrm{m} / \mathrm{s}^{2}$

$H \quad-$ height, $\mathrm{m}$

${ }^{*}$ Corresponding Author. E-mail: hbiel@imp.gda.pl 


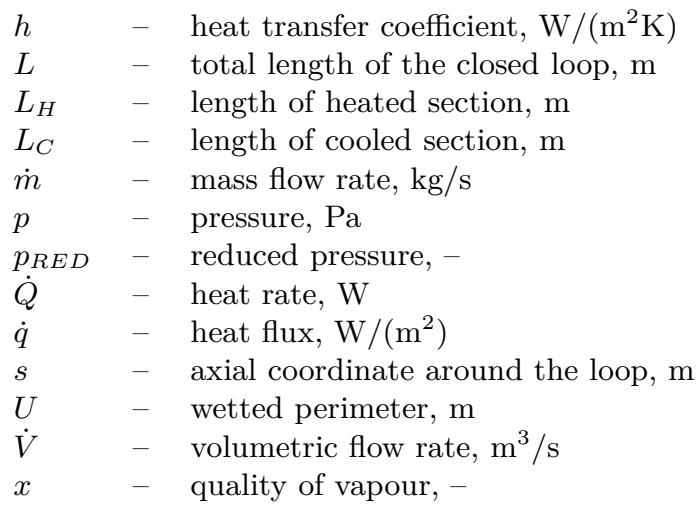

\section{Greek symbols}

$\alpha \quad-\quad$ void fraction, -

$\rho \quad-\quad$ mass density, $\mathrm{kg} / \mathrm{m}^{3}$

$\tau_{w} \quad-\quad$ wall shear stress, $\mathrm{N} / \mathrm{m}^{2}$

\section{Subscripts}

$\begin{array}{lll}C & - & \text { cooler } \\ H & - & \text { heater } \\ L & - & \text { liquid } \\ V & - & \text { vapour } \\ T P, 2 p & - & \text { two-phase } \\ L 0 & - & \text { liquid phase only } \\ T P B & - & \text { two-phase boiling } \\ T P C & - & \text { two-phase cooling } \\ R E F & - & \text { reference } \\ P B & - & \text { pool boiling }\end{array}$

\section{Introduction}

This paper is an extension of our earlier contributions published in Archives of Thermodynamics [4-5]. These articles provide a discussion of conventional tubes of the thermosyphon loop. In case of minichannels constituting the thermosyphon, it is necessary to use new correlations for void fraction and the local two-phase friction coefficient in two-phase region, and local heat transfer coefficient for flow boiling and condensation.

Fluid flow in a thermosyphon loop is created by the buoyancy forces that evolve from density gradients induced by temperature differences in the heating and cooling sections of the loop. The minipump can be used if the mass flux is not high enough to transport heat from evaporator to condenser. Therefore, the minipump promotes natural circulation. A closed 
thermosyphon loop consists of a heater, cooler and minipump, connected with tubes. The lower heater can be a CPU processor located on the motherboard of personal computer. The cooler can be placed above the heater on the computer chassis. Heat exchangers are connected by tubes in which the liquid refrigerant is in operation.

The single- and two-phase thermosyphon loops find many industrial applications, such as for example: steam generators, thermosyphon reboilers, emergency cooling systems in nuclear reactor cores and reflux boiling systems in light water reactor cores, solar heating and cooling systems, geothermal energy generation [17] and thermal diodes [2,3]. The thermal diode is a device, which allows the heat to be transferred in one direction, and blocks the heat flow in the opposite direction. Thermosyphons can be designed as a closed loop. The closed-loop thermosyphon is also known as a 'liquid fin' [16]. The increasing integration of electronic systems requires improved cooling technologies. Because of increased power levels, miniaturization of the electronic devices and typical cooling techniques, the heat removal due to conduction is not able to transfer such a high heat flux. Thermosyphon cooling is an alternative cooling technology of dissipating high local heat fluxes.

The thermosyphon effect for cooling electronic devices can be applied in innovative miniature loop heat pipe (mLHP) with the evaporator located on the loop below the condenser (Fig. 1). The prototype of mLHP consists of a flat minievaporator and capillary pump. The porous wick material is placed inside the capillary pump. The complete condensation of the medium takes place in a minicondenser. Both the mini-evaporator and minicooler are connected to the separate liquid and vapour channels. The high friction losses in mLHP can be reduced because the liquid/vapour phase flow in the separated channels and the porous wick is only present in minievaporator. The flat-shaped mini-evaporator is integrated with a capillary pump. The wicks generate the capillary pumping pressure, which is required to transport a working fluid along mLHP.

The thermosyphon effect can also be applied in concept of micro-CHPcogeneration where evaporator is located below condenser (Fig. 2). The use of capillary forces for pumping of the working fluid in the Clausius-Rankine cycle is a new idea that allows the reduction or even the elimination of the pumping device in such cycles. It is also possible to exploit the gravity force to support the operation of a circulation pump by placing the evaporator below the condenser and creating the thermosyphon loop. 


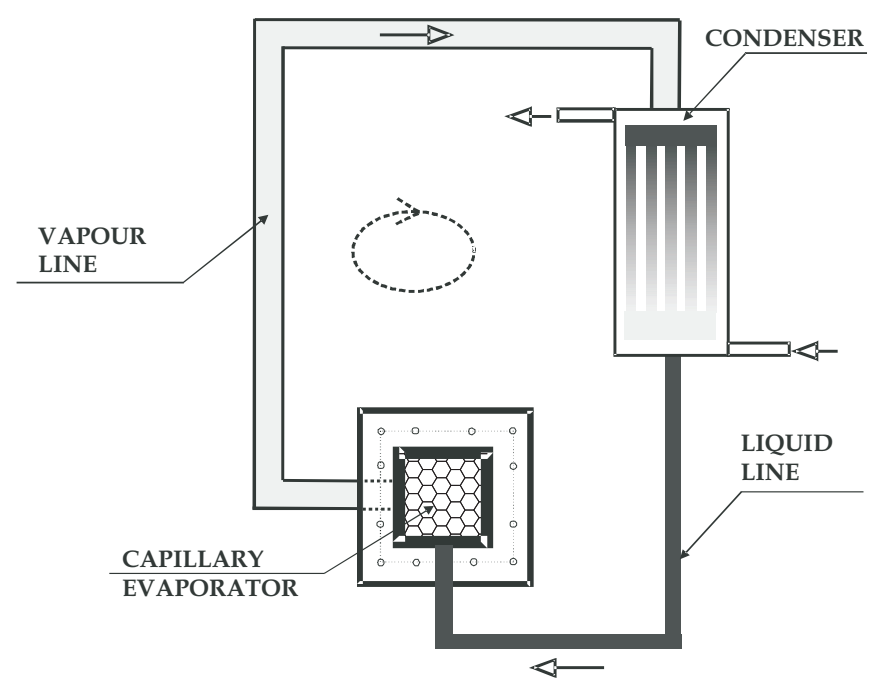

Figure 1: Idea scheme of miniature loop heat pipe (mLHP) with thermosyphon loop.

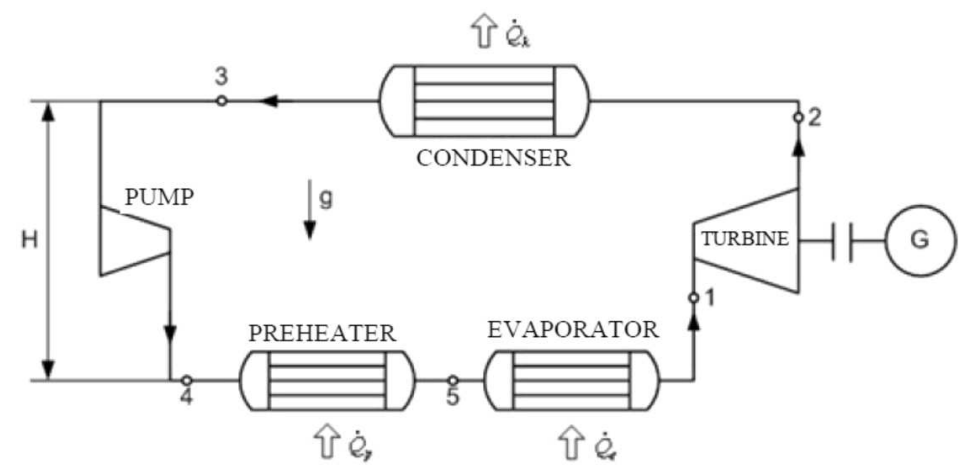

Figure 2: Structural scheme of CHP with LHP and thermosyphon loop [20].

The specific aim of this paper is to report on a new cooling method of the computer using the thermosyphon loop with minichannels and minipump. The thermosyphon cooling system used in computer can be modeled by the rectangular thermosyphon loop with minichannels and minipump heated at the bottom vertical side and cooled at the upper vertical side. The case presented here is a new aspect of computer cooling. The trend toward miniaturization of electronic components provides the adoption of advanced cooling solutions. 


\section{The model of the two-phase thermosyphon loop with minichannels and minipump}

A schematic diagram of a one-dimensional model of the two-phase thermosyphon loop with minichannels and minipump heated from lower vertical section and cooled from upper vertical section is shown in Fig. 3. Fluid flow in a thermosyphon loop is created by the buoyancy forces that evolve from the density gradients induced by temperature differences in the heating and cooling sections of the loop. The minipump can be used if the mass flux is not high enough to transport heat from evaporator to condenser. Therefore, the minipump enhances natural circulation. The thermosyphon loop is heated from lower vertical section $\left(s_{0} \leq s \leq s_{1}\right)$ by a constant heat flux: $\dot{q}_{H}$ and cooled in the upper vertical section $\left(s_{4} \leq s \leq s_{5}\right)$ by a constant heat flux: $\dot{q}_{C}$. The constant heat fluxes $\dot{q}_{H}$ and $\dot{q}_{C}$ are applied in the crosssection area per heated and cooled length: $L_{H}$ and $L_{C}$. The heated and cooled parts of the thermosyphon loop are connected by perfectly insulated channels $\left(s_{1} \leq s \leq s_{4}, \quad s_{5} \leq s \leq s_{8}\right)$.

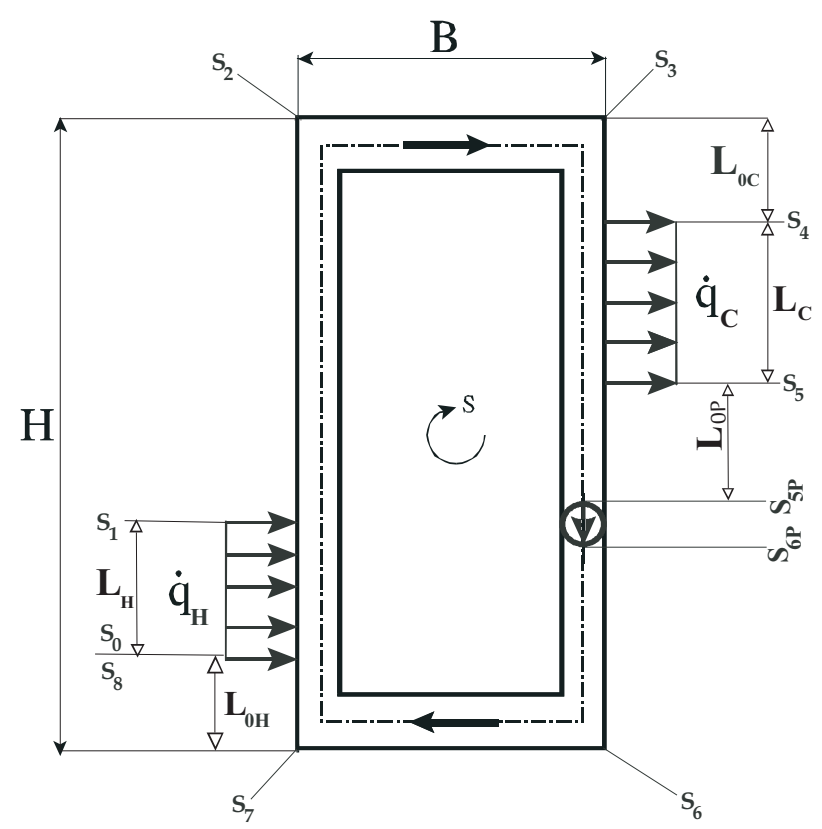

Figure 3: Model of the two-phase thermosyphon loop with minichannels and minipump heated from lower vertical section and cooled from upper vertical section. 
As shown in Fig. 3 the space coordinate s circulates around the closed loop. The total length of the loop is denoted by $L$, the cross-section area of the channel by $A$ and the wetted perimeter by $U$. Both superheating and subcooling are neglected and a linearly varying quality function $x(s)$ are assumed according to [3-10].

\section{Governing equations}

The one-dimensional, steady-state governing equations for thermosyphon loop with minichannels and minipump can be written as $[3-10,18]$ :

$$
\left\{\begin{array}{l}
\frac{d \dot{m}}{d s}=0, \\
-\frac{d p}{d s}=\underbrace{\frac{U}{A} \tau_{w}}_{\text {friction term }}+\underbrace{\frac{\dot{m}}{A} \frac{d}{d s}\left[\frac{(1-x)^{2}}{(1-\alpha) \rho_{L}}+\frac{x^{2}}{\alpha \rho_{V}}\right]}_{\text {acceleration term }}+\underbrace{\beta g\left[(1-\alpha) \rho_{L}+\alpha \rho_{V}\right]}_{\text {gravitation term }} \\
\frac{d}{d s}\left(\frac{\dot{m}}{A} h\right)= \begin{cases}0 & \text { for insulated regions } \\
\frac{U}{A} \dot{q} & \text { for heated and cooled regions }\end{cases}
\end{array}\right.
$$

where $\beta=0$ for $\vec{e} \perp \vec{g} ; \quad \beta=(+1)$ for $\vec{e} \uparrow \wedge \vec{g} \downarrow ; \quad \beta=(-1)$ for $\vec{e} \downarrow \wedge \vec{g} \downarrow$ (where $\vec{g}$ - vector acceleration, $\vec{e}$ - versor, $\uparrow-$ sense of a vector).

In the equation of motion of the thermosyphon loop with natural circulation, the pressure term of integration around the loop is equal to zero

$$
\oint\left(\frac{d p}{d s}\right) d s=0 .
$$

For the thermosyphon loop with minipump the pressure term is

$$
\oint\left(\frac{d p}{d s}\right) d s=\Delta p_{P U M P}=\rho_{L} g H_{P U M P} ; H_{P U M P}=H_{M A X}\left[1-\left(\frac{\dot{V}}{\dot{V}_{M A X}}\right)^{2}\right]
$$

with $H_{M A X}, \dot{V}_{M A X}$ from minipump curve [11].

The gravitational term in the momentum equation (1) can be expressed 
as

$$
\begin{aligned}
& \oint\{\beta g \rho\} d s=g\left(\rho_{V}-\rho_{L}\right)\left\{\left(s_{1}-s_{0}\right) \bar{\alpha}_{\left\langle s_{0} ; s_{1}\right\rangle}-\left(s_{5}-s_{4}\right) \bar{\alpha}_{\left\langle s_{4} ; s_{5}\right\rangle}+\right. \\
& \left.+\left[\left(s_{2}-s_{1}\right)-\left(s_{4}-s_{3}\right)\right] \bar{\alpha}_{\left\langle s_{1} ; s_{4}\right\rangle}\right\}=0
\end{aligned}
$$

where

$$
\bar{\alpha}_{\left\langle s_{i} ; s_{j}\right\rangle}=\frac{1}{\left(s_{j}-s_{i}\right)} \int_{s_{i}}^{s_{j}} \alpha_{\left\langle s_{i} ; s_{j}\right\rangle}(s) d s .
$$

The frictional component of the pressure gradient in two-phase regions was calculated using the two-phase separate model. Due to friction of fluid, the pressure gradient in two-phase regions can be written as follows $[14,18]$ :

$$
\frac{U}{A} \tau_{w}=\left(\frac{-d p}{d s}\right)_{2 p}=R\left(\frac{-d p}{d s}\right)_{L 0},
$$

where $R$ is the local two-phase flow multiplier. $\left(\frac{d p}{d s}\right)_{L 0}$ is the liquid only frictional pressure gradient calculated for the liquid total mass flow rate. After integrating the friction term around the loop, we obtain

$$
\begin{aligned}
\oint\left(\frac{U}{A} \tau_{w}\right) d s & =\left(\frac{d p}{d s}\right)_{L 0}\left\{\left(s_{1}-s_{0}\right) \bar{R}_{\left\langle s_{0} ; s_{1}\right\rangle}+\left(s_{4}-s_{1}\right) \bar{R}_{\left\langle s_{1} ; s_{4}\right\rangle}\right. \\
& \left.+\left(s_{5}-s_{4}\right) \bar{R}_{\left\langle s_{4} ; s_{5}\right\rangle}+\left(s_{8}-s_{5}\right)\right\}
\end{aligned}
$$

where

$$
\bar{R}_{\left\langle s_{i} ; s_{j}\right\rangle}=\frac{1}{\left(s_{j}-s_{i}\right)} \int_{s_{i}}^{s_{j}} R(s) d s .
$$

Substituting Eqs. (2) and (5) into the momentum Eq. (1) gives

$$
\begin{aligned}
& \left(\frac{d p}{d s}\right)_{L 0}\left\{\left(s_{1}-s_{0}\right) \bar{R}_{\left\langle s_{0} ; s_{1}\right\rangle}+\left(s_{4}-s_{1}\right) \bar{R}_{\left\langle s_{1} ; s_{4}\right\rangle}+\left(s_{5}-s_{4}\right) \bar{R}_{\left\langle s_{4} ; s_{5}\right\rangle}+\right. \\
& \left.+\left(s_{8}-s_{5}\right)\right\}+g\left(\rho_{V}-\rho_{L}\right)\left\{\left(s_{1}-s_{0}\right) \bar{\alpha}_{\left\langle s_{0} ; s_{1}\right\rangle}-\left(s_{5}-s_{4}\right) \bar{\alpha}_{\left\langle s_{4} ; s_{5}\right\rangle}\right. \\
& \left.+\left[\left(s_{2}-s_{1}\right)-\left(s_{4}-s_{3}\right)\right] \bar{\alpha}_{\left\langle s_{1} ; s_{4}\right\rangle}\right\}+\rho_{L} g H_{P U M P}=0 .
\end{aligned}
$$

The El-Hajal et al. [13] empirical correlation for the void fraction was applied. The local two-phase friction coefficient in two-phase adiabatic region was calculated using the Zhang and Webb [25] formula. In twophase heating and cooling sections the local two-phase friction coefficient was calculated using the Tran et al. [23] and Cavallini et al. [12] formula, respectively (Tab. 1). The working fluid was distilled water. A miniature pump curve from (Blanchard et. al. [11]) was included in calculations. 
Table 1: Minichannels. Correlation for the void fraction and the friction pressure drop of two-phase flow.

\begin{tabular}{|c|c|c|}
\hline Researcher & Correlation & \\
\hline El-Hajal et al. [13] & $\begin{array}{l}\alpha_{H A J A L}=\frac{\alpha_{H O M}-\alpha_{S T E I N E R}}{\ln \left(\frac{\alpha_{H O M}}{\alpha_{S T E I N E R}}\right)} ; \alpha_{H O M}=\frac{1}{1+\frac{1-x}{x}\left(\frac{\rho_{V}}{\rho_{L}}\right)} \\
\quad \alpha_{S T E I N E R}=\left(\frac{x}{\rho_{V}}\right) \times \\
\quad \times\left\{[1+0.12(1-x)]\left[\frac{x}{\rho_{V}}+\frac{1-x}{\rho_{L}}\right]+\right. \\
\left.\quad+\frac{1.18 \cdot(1-x)\left[g \cdot \sigma\left(\rho_{L}-\rho_{V}\right)\right]^{0.25}}{\dot{G}\left(\rho_{L}\right)^{0.5}}\right\}^{(-1)}\end{array}$ & 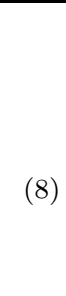 \\
\hline $\begin{array}{l}\text { Zhang and Webb } \\
{[25]}\end{array}$ & $\begin{array}{l}\left(\frac{d p}{d l}\right)_{2 p}^{Z-W}=\Phi_{L 0}^{2}\left(\frac{d p}{d z}\right)_{L 0} \\
\Phi_{L 0}^{2}=(1-x)^{2}+2.87(x)^{2}\left(\frac{P}{P_{C R I T}}\right)^{(-1)}+ \\
+1.68(1-x)^{0.25}\left(\frac{P}{P_{C R I T}}\right)^{(-1.64)}\end{array}$ & (9) \\
\hline Tran et al. [23] & $\begin{array}{l}\left(\frac{d p}{d l}\right)_{2 p}^{T R A N}=\Phi_{L 0}^{2}\left(\frac{d p}{d z}\right)_{L 0} ; \\
\Phi_{L 0}^{2}=1+\left(4.3 Y^{2}-1\right)\left[N_{C O N F}(x)^{0.875}(1-x)^{0.875}+(x)^{1.75}\right] \\
N_{C O N F}=\frac{\left[\frac{\sigma}{g \cdot\left(\rho_{L}-\rho_{V}\right)}\right]^{0.5}}{D} ; Y=\sqrt{\left(\frac{d p}{d z}\right)_{V 0} /\left(\frac{d p}{d z}\right)_{L 0}}\end{array}$ & (10) \\
\hline Cavallini et al. [12] & $\begin{array}{l}\left(\frac{d p}{d l}\right)=\Phi_{L 0}^{2}\left(\frac{d p}{d z}\right)_{L 0} ; \Phi_{L 0}^{2}=E+\frac{1.262 . F H}{(\mathrm{We})^{0.1458}} \\
(\mathrm{We})=\frac{\dot{G}^{2} D}{\sigma \rho_{V}} ; E=(1-x)^{2}+x^{2} \frac{\rho_{L} f_{V 0}}{\rho_{V} f_{L 0}} ; \\
F=x^{0.6978} ; H=\left(\frac{\rho_{L}}{\rho_{V}}\right)^{0.3278}\left(\frac{\mu_{V}}{\mu_{L}}\right)^{(-1.181)}\left(1-\frac{\mu_{V}}{\mu_{L}}\right)^{3.477}\end{array}$ & (11) \\
\hline
\end{tabular}

\section{Results}

The mass flux distribution, $\dot{G}$, versus heat flux, $\dot{q}_{H}$, for loop with the minipump and gravity loop without the minipump were obtained numerically under the steady-state condition using separate model, as is shown 
in Fig. 4. For thermosyphon loop without the minipump the two-flow regimes can be clearly identified (Fig. 4): GDR - gravity dominant regime and FDR - friction dominant regime. The presence of GDR and FDR dominant regime was also demonstrated experimentally by Agostini and Ferreira [1]. The explanation of existing regimes were given by Vijayan et. al. [24].

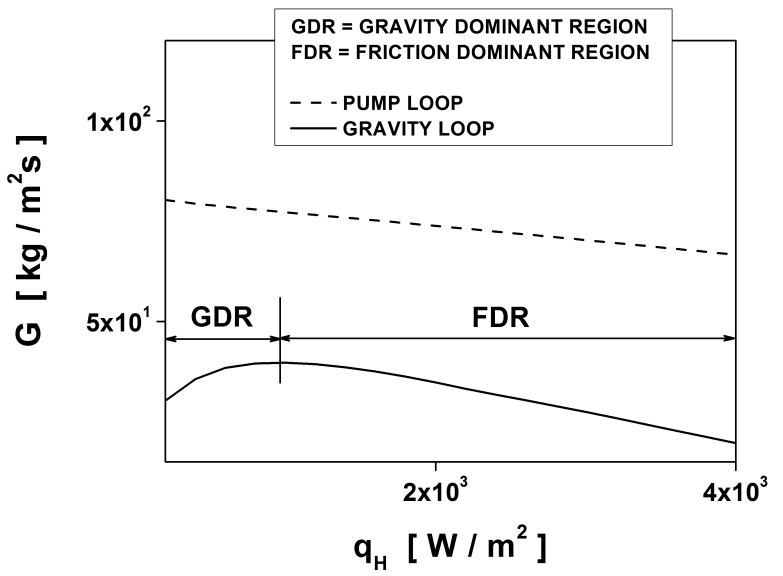

Figure 4: Mass flux $\dot{G}$ as a function of $\dot{q}_{H}(L=0.2 \mathrm{~m}, B=0.02 \mathrm{~m}, H=0.08 \mathrm{~m}$, $D=0.0025 \mathrm{~m})$.

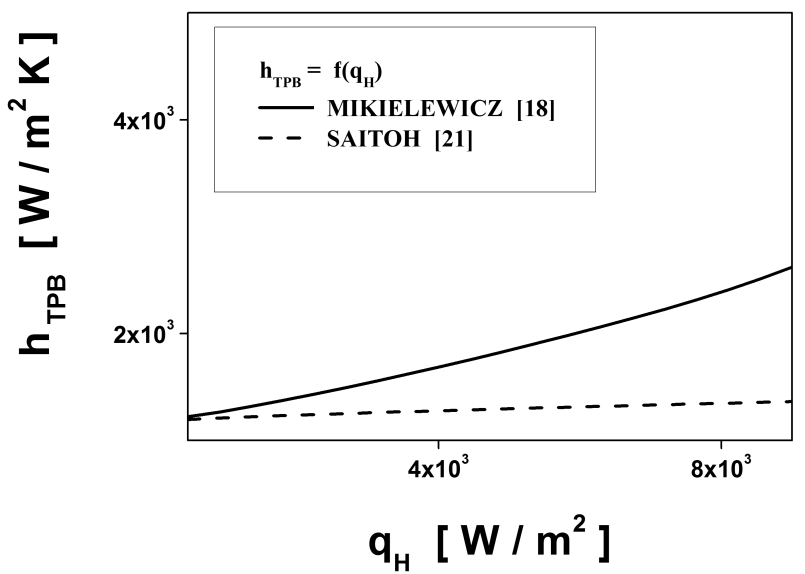

Figure 5: Heat transfer coefficient $h_{T P B}$ as a function of $\dot{q}_{H}$ for heater. 
Table 2: Minichannels. Correlation for the heat transfer coefficient for flow boiling.

\begin{tabular}{|c|c|}
\hline Researcher & Correlation \\
\hline $\begin{array}{l}\text { Mikielewicz et al., } \\
{[19]}\end{array}$ & $\begin{array}{l}\frac{h_{T P B}^{J M}}{h_{R E F}}=\sqrt{\left(R_{M-S}\right)^{n}+\frac{1}{1+P}\left(\frac{h_{P B}}{h_{R E F}}\right)^{2}} ; \\
R_{M-S}=\left[1+2\left(\frac{1}{f_{1}}-1\right) x\left(N_{C O N F}\right)^{(-1)}\right](1-x)^{\frac{1}{3}}+x^{3} \frac{1}{f_{1 z}} ; \\
L A M \Rightarrow n=2 ; \alpha_{R E F}^{L A M}=4.36\left(\frac{\lambda_{L}}{D}\right) ; f_{1}^{L A M}=\left(\frac{\mu_{L}}{\mu_{V}}\right)\left(\frac{\rho_{V}}{\rho_{L}}\right)^{2} ; \\
f_{1 z}^{L A M}=\left(\frac{\lambda_{L}}{\lambda_{V}}\right) ; \\
\quad T U R \Rightarrow n=0.76 ; h_{R E F}=0.023 \frac{\lambda_{L}}{D}\left(\operatorname{Re}_{L 0}\right)^{0.8}\left(\operatorname{Pr}_{L}\right)^{\frac{1}{3}} ; \\
f_{1}^{T U R}=\left(\frac{\mu_{L}}{\mu_{V}}\right)^{0.25}\left(\frac{\rho_{V}}{\rho_{L}}\right) ; f_{1 z}^{T U R}=\left(\frac{\mu_{V}}{\mu_{L}}\right)^{\frac{7}{15}}\left(\frac{c_{p L}}{c_{p V}}\right)^{\frac{1}{3}}\left(\frac{\lambda_{L}}{\lambda_{V}}\right)^{\frac{3}{2}} ; \\
P=2.53 \times 10^{(-3)}\left(\operatorname{Re}_{L 0}\right)^{1.17}(\mathrm{Bo})^{0.6}\left(R_{M-S}-1\right)^{(-0.65)} ; \\
(\mathrm{Bo})=\frac{\dot{q}}{G r} ;\left(\operatorname{Re}_{L 0}\right)=\frac{\dot{G} d}{\mu_{L}} ; \\
h_{P B}=55 \dot{q}^{0.67} M^{(-0.5)}\left(\frac{P_{n}}{P_{C R I T}}\right)^{0.12}\left[-\log _{10}\left(\frac{P_{n}}{P_{C R I T}}\right)\right]^{(-0.55)} ;\end{array}$ \\
\hline Saitoh et al., [21] & 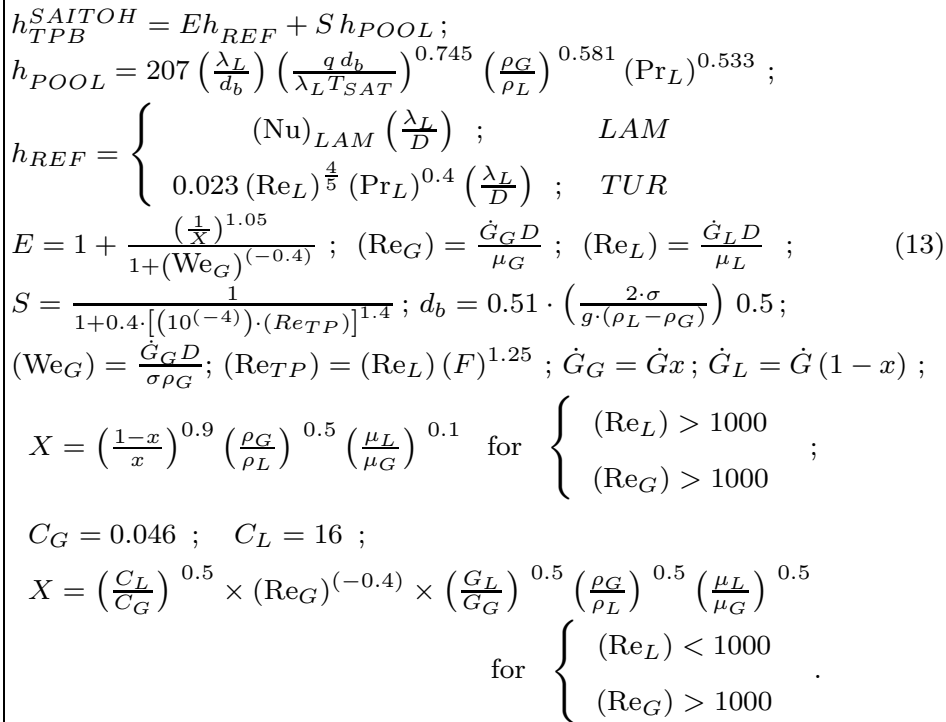 \\
\hline
\end{tabular}

The heat transfer coefficient for flow boiling in evaporator with minichannels $h_{T P B}$ distributions versus heat flux $\dot{q}_{H}$ in evaporator $\left(s_{0} \leq s \leq s_{1}\right)$ was numerically obtained using Mikielewicz et al. [19] and Saitoh et al. [21] correlations (Tab. 2). The results obtained for minichannels are presented in Fig. 5. The results show that the distributions of heat transfer coefficient for flow boiling in the heater with minichannels calculated using the 
Mikielewicz et al. [19] formula, the modified Saitoh et al. formula [21] have the same trend. According to the results of this study, mass flow increases with increasing heat flux. The similar effect is reported by Khodabandeh [15]. He suggested that the observed trend indicates on the dominance of nucleate boiling.

The heat transfer coefficient in flow condensation in cooler with minichannels $h_{T P C}$ distributions versus heat flux $\dot{q}_{C}$ in condenser $\left(s_{4} \leq s \leq s_{5}\right)$ was calculated numerically using Mikielewicz et al. [19] and Shah [22] correlations (Tab. 3).

Table 3: Minichannels. Correlation for the condensation heat transfer coefficient.

\begin{tabular}{|l|ll|}
\hline \multicolumn{1}{|c|}{ Researcher } & \multicolumn{1}{|c|}{ Correlation } \\
\hline \hline Mikielewicz et al. $[19]$ & $\frac{h_{T P B}^{J M}}{h_{R E F}} \sqrt{\left(R_{M-S}\right)^{n}}$ \\
\hline Shah $[22]$ & $h_{T P C}^{S H A H}=h_{L 0} \times\left[(1-x)^{0.8}+\frac{3.8(x)^{0.76}(1-x)^{0.04}}{\left(p_{R E D}\right)^{0.38}}\right]$ & (14) \\
\hline
\end{tabular}

The results obtained for minichannels are presented in Fig. 6. The heat transfer coefficient for flow condensation in minichannels slowly increases with increasing heat flux in the cooler $\left\langle s_{4} ; s_{5}\right\rangle$ for the Mikielewicz et al. [19] formula, the modified Shah formula [22] as it shown in Fig. 6. Comparison of these two distributions show that the results have similar tendency.

\section{Conclusions}

The results of the study shows that the one-dimensional two-phase separate model can be used to describe heat transfer and fluid flow in the thermosyphon loop with minichannels and minipump heated from lower vertical section and cooled from upper vertical section. The quality of vapour in the two-phase regions is assumed to be a linear function of the coordinate around the loop.

In order to evaluate performance of the thermosyphon loop with minichannels the following correlation have been used: El-Hajal et al. [13] correlation for void fraction, Zhang and Webb [25] correlation for the friction pressure drop of two-phase flow in adiabatic region, Tran et al. [23] and Cavallini et al. [12] correlation for the friction pressure drop of two-phase flow in heat- 


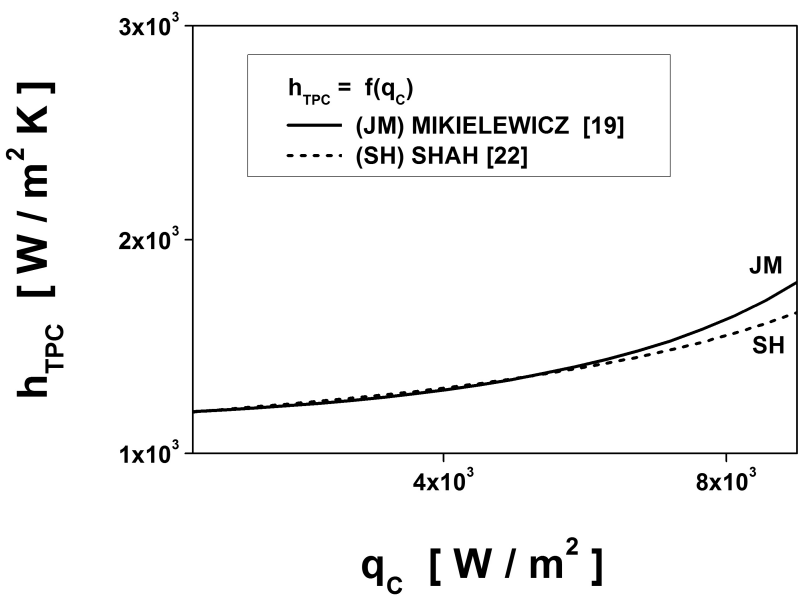

Figure 6: Cooler. Heat transfer coefficient $h_{T P C}$ as a function of $\dot{q}_{C}$.

ing and cooling section, respectively (Fig. 4), and Mikielewicz et al. [19] and Saitoh et al. [21] correlations for the heat transfer coefficient for flow boiling in evaporator with minichannels (Fig. 5), Mikielewicz et al. [19] and Shah [22] correlations for the heat transfer coefficient in flow condensation in cooler with minichannels (Fig. 6). Distilled water as the working fluid was used in calculations.

In case of thermosyphon loop with minichannels and without a minipump the distribution of the mass flux against the heat flux approaches a maximum and then slowly decreases and the two-flow regimes can be clearly identified as the gravity dominant regime (GDR) and the friction dominant regime (FDR) as presented in Fig. 4. If the mass flow rate is not high enough to circulate the necessary fluid to transport heat from evaporator to condenser, the minipump can be used to promotes natural circulation.

For thermosyphon loop with minichannels and minipump at steadystate condition as it is demonstrated in Fig. 4, the mass flux, $\dot{G}$, decreases with increasing heat flux, $\dot{q}_{H}$, for friction dominant region (FDR).

The heat transfer coefficient for flow boiling in evaporator with minichannels increases with increasing heat flux (Fig. 5). The heat transfer coefficient for flow condensation in cooler with minichannels slowly increases with increasing heat flux (Fig. 6).

The numerical analysis of the model of thermosyphon loop with minichannels and minipump heated from lower vertical section and cooled from up- 
per vertical section indicates that the presented solution is a power tool for increasing the effectiveness of computer cooling. The offered variant has both a simple design and manufacture and can be a theoretical basis for further work on prototype testing.

Acknowledgement The work presented in the paper was funded from the National Science Centre Poland: Project No: NCN-UMO-2011/01/B/ /ST8/06856.

Received 10 August 2015

\section{References}

[1] Agostini F., Ferreira E.: Non intrusive measurement of the mass flow rate inside a closed loop two-phase thermosyphon. In: Proc. 8th Minsk Int. Sem. 'Heat Pipes, Heat Pumps, Refrigerators, Power Sources', Minsk, Sept. 12-15, 2011.

[2] Bieliński H., Mikielewicz J.: Natural convection of thermal diode. Arch. Thermodyn. 16(1995), 3-4.

[3] Bieliński H., Mikielewicz J.: New solutions of thermal diode with natural laminar circulation. Arch. Thermodyn. 22(2001), 1-2, 89-106.

[4] Bieliński H., Mikielewicz J.: The effect of geometrical parameters on the mass flux in a two phase thermosyphon loop heated from one side. Arch. Thermodyn. 29(2004), 1, 59-68.

[5] Bieliński H., Mikielewicz J.: Natural circulation in two-phase thermosyphon loop heated from below. Arch. Thermodyn. 25(2004), 3, 15-26.

[6] Bieliński H., Mikielewicz J.: A two-phase thermosyphon loop with side heating. Inżynieria Chemiczna i Procesowa 26(2005), 339-351 (in Polish).

[7] Bieliński H., Mikielewicz J.: Energetic analysis of natural circulation in the closed loop thermosyphon with minichannels. Arch. Energ. 40(2010), 3, 3-10.

[8] Bieliński H., Mikielewicz J.: Computer cooling using a two phase minichannel thermosyphon loop heated from horizontal and vertical sides and cooled from vertical side. Arch. Thermodyn. 31(2010), 4, 51-59.

[9] Bieliński H., Mikielewicz J.: A two phase thermosyphon loop with minichannels heated from vertical side and cooled from horizontal side. Inżynieria Chemiczna i Procesowa 31(2010), 535-551.

[10] Bieliński H., Mikielewicz J.: Natural circulation in single and two phase thermosyphon loop with conventional tubes and minichannels. In: Heat Transfer. Mathematical Modeling, Numerical Methods and Information Technology (A. Belmiloudi Ed.), InTech 2011 (ISBN 978-953-307-550-1), 475-496,

[11] Blanchard D.B., Ligrani P.M., Gale B.K.: Performance and Development of a Miniature Rotary Shaft Pump (RSP). In: Proc. 2004 ASME Int. Mech. Eng. Cong. RD\&D Expo, Nov. 13-20, 2004, Anaheim, California USA. 
[12] Cavallini A., Censi G., Del Col D., Doretti L., Longo G.A., Rossetto L., ZILIO C.: Condensation inside and outside smooth and enhanced tubes - a review of recent research. Int. J. Refrigeration, 26(2003), 4, 373-392.

[13] El-Hajal J., Thome J.R., Cavallini A.: Condensation in horizontal tubes, part 1; Two-phase flow pattern map.. Int. J. Heat Mass Tran. 46(2003), 18, 3349-3363.

[14] Kandlikar S.G., Garimella S., Li D., Colin S., King M. R.: Heat Transfer and Fluid Flow in Minichannels and Microchannels. Elsever 2006.

[15] Khodabandeh R.: Heat transfer in the evaporator of an advanced two-phase thermosyphon loop. Int. J. Refrig. 28(2005), 190-202.

[16] Madejski J., Mikielewicz J.: Liquid fin a new device for heat transfer equipment. Int. J. Heat Mass Tran. 14(1971), 357-363.

[17] Mertol A., Greif R.: A review of natural circulation loops. In: Natural Convection: Fundamentals and Applications, 1985, 1033-1071,.

[18] Mikielewicz J.: Modelling of the heat-flow processes. Maszyny Przepływowe 17, Ossolineum, Wrocław 1995.

[19] Mikielewicz D., Mikielewicz J., Tesmar J.: Improwed semi-empirical method for determination of heat transfer coefficient in flow boiling in conventional and small diameter tubes. Int. J. Heat Mass Tran. 50(2007), 3949-3956.

[20] Mikielewicz D., Szymański P., BŁauciak K., Wajs J., Mikielewicz J., IhnaTOWICZ E.: The new concept of capillary forces aided evaporator for application in domestic organic Rankine cycle. Int. J. Heat Pipe Sci. Techn. 1(2010), 4, 359-373.

[21] Saitoh S., Daiguji H., Hihara E.: Correlation for boiling heat transfer of $R$ 134 a in horizontal tubes including effect of tube diameter. Int. J. Heat Mass Tran. 50(2007), 5215-5225.

[22] Sнан M.M.: A general correlation for heat transfer during film condensation inside pipes. Int. J. Heat Mass Tran. 22(1979), 547-556

[23] Tran T.N., Chyu M.C., Wambsganss M.W., France D.M.: Two phase pressure drop of refrigerants during flow boiling in small channels: an experimental investigations and correlation development. Int. J. Multiphas. Flow 26(2000), 11, 1739-1754.

[24] Vijayan P.K., Nayak A.K., Saha D., Gartia M.R.: Effect of loop diameter on the steady state and stability behaviour of single-phase and two-phase natural circulation loops. Hindawi Science and Technology of Nuclear Installations 2008, Article ID 672704, Hindawi 2008.

[25] Zhang M., WebB R.L.: Correlation of two-phase friction for refrigerants in smalldiameter tubes. Exp. Therm. Fluid Sci. 25(2001), 131-139. 